\title{
Gender-specific contributing risk factors and outcome of female cryptococcal meningoencephalitis patients
}

Hui Zheng ${ }^{1 *}$ D, Mingyue Li ${ }^{1}$, Dongmei Wang ${ }^{1}$, Jia ling Yang ${ }^{1}$, Qiong Chen ${ }^{1}$, Xiaomei Zhang ${ }^{1}$, Yang Man ${ }^{1}$, Junying Lao ${ }^{2}$, Ningfen Chen ${ }^{2}$ and Suyue Pan ${ }^{1 *}$

\begin{abstract}
Background: Although male predominance was documented in previous studies on cryptococcal meningoencephalitis (CM), there has been no statistical study about female CM patients despite recently noticeable increase in female prevalence. In the current study, we aimed to investigate the independent gender-specific contributing risk factors for onset of CM and factors related to survival time in female patients by chosen statistical tools.

Methods: There have been 108 patients diagnosed with CM from July 1, 1998 to June 30, 2013 in Nanfang Hospital that were included in our study. This 15-year retrospective study compared demographic and clinical features of 31 female patients with 77 males. Multivariate analysis was performed for detection of the contributors to the onset of CM in female patients. The independent variables for multivariate analysis were selected according to statistical significance in univariate analysis. Furthermore, Cox regression model was used to evaluate the factors related to survival length.

Results: Use of corticosteroids or other immunosuppressants (32.3\% versus $11.7 \% ; p=0.011$ ) and history of systemic lupus erythematosus (SLE) and other autoimmune diseases (29\% versus 3.9\%; $p<0.001$ ) were more common in females, but only the history of SLE or other autoimmune diseases was significant (OR 10.59, $95 \% \mathrm{Cl}$ 1.49-74.77, $p=0.02$ ) by multivariate analysis. The ratio of cerebrospinal fluid (CSF) glucose-to-blood glucose was related to the survival time $(p=0.03,95 \% \mathrm{Cl} 0-0.71)$.

Conclusions: The results showed that the history of SLE or other autoimmune diseases rather than chronic use of corticosteroids and/or immunosuppressants was the independent gender-specific contributing risk factor in female CM patients. Therefore, more attention should be made to the prevention of infection from the genus Cryptococcus spp. in female patients with SLE or other autoimmune diseases. In addition, decreased ratio of CSF glucose-to-blood glucose before antifungal therapy predicted the worse prognosis.
\end{abstract}

Keywords: Cryptococcal meningoencephalitis, Female, Gender-specific, Retrospective research, Contributing risk factor, Survival length

\footnotetext{
* Correspondence: gzzhenghui0527@gmail.com; pansuyue82@qq.com

'Department of Neurology, Nanfang Hospital, Southern Medical University,

No.1838 North Guangzhou Avenue, Guangzhou City, Guangdong Province,

People's Republic of China

Full list of author information is available at the end of the article
}

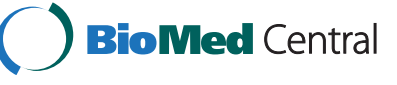

(c) 2016 Zheng et al. Open Access This article is distributed under the terms of the Creative Commons Attribution 4.0 International License (http://creativecommons.org/licenses/by/4.0/), which permits unrestricted use, distribution, and reproduction in any medium, provided you give appropriate credit to the original author(s) and the source, provide a link to the Creative Commons license, and indicate if changes were made. The Creative Commons Public Domain Dedication waiver (http://creativecommons.org/publicdomain/zero/1.0/) applies to the data made available in this article, unless otherwise stated. 


\section{Background}

The genus Cryptococcus spp. is an encapsulated yeast-like fungus which causes life-threatening diseases and can infect some important organs in the human body [1, 2]. Its infection of the central nervous system (CNS)-cryptococcal meningoencephalitis (CM) - is one of the most common fungal infection causing morbidity and mortality worldwide [3, 4].

Many diseases have a different frequency and severity between female and male $[5,6]$, a tendency featured in CM. Male predominance was apparent in most of the previous CM studies in different countries [1,7-10], but recently the noticeable increase in female prevalence was seen, as suggested by the decreased male-to-female ratio [10, 11]. Until now, several reports have called attention to the female $\mathrm{CM}$ patients [12-16], but no statistical study of these patients was found.

In the current study, by observing the gender differences of the epidemiological characteristics, clinical features and outcome in patients diagnosed with $\mathrm{CM}$ in Nanfang Hospital in China, we firstly demonstrated the independent gender-specific contributing risk factors for the onset of $\mathrm{CM}$ and factors related to survival time in female CM patients by chosen statistical tools.

\section{Methods}

\section{Data source and study population}

In this retrospective observational study, 108 patients diagnosed with CM from Nanfang Hospital were included between July 1, 1998 to June 30, 2013 (15 years). Their medical records were reviewed to extract genderspecific demographic and clinical features, including potential risk factors, symptoms, cerebrospinal fluid (CSF) analysis, electroencephalograph (EEG) and magnetic resonance imaging (MRI) results. Furthermore, the probable contributing risk factors and survival time of female CM patients were analyzed. All patients or their family members signed a written consent in accordance with the ethical committee standards during their hospital stay or outpatient follow-up and the written approval for this study was obtained from the ethics committee of the Nanfang Hospital.

\section{Study criteria}

CM was defined by either of the following criteria: (1) isolation of the genus Cryptococcus spp. from previous or current cerebrospinal fluid cultures, followed by a positive CSF cryptococcal antibody, positive CSF India ink staining, or positive CSF Aley new blue dye staining and clinical features of meningoencephalitis; or (2) isolation of the genus Cryptococcus spp. in blood culture with clinical presentations of meningoencephalitis and typical CSF features [17].
Patients were regarded as "with potential risk factors" when they have HIV infection, malignancies, cirrhosis, organ transplantation, end-stage renal failure autoimmune disorder, diabetes mellitus, idiopathic CD4 T-cell lymphopenia, sarcoidosis, chronic usage of corticosteroids or other immunosuppressive therapy [18], and systemic lupus erythematosus (SLE) or other systemic autoimmune diseases, chronic kidney diseases, pregnant, mycosis infection of other system, drug addiction, etc.

Bubble sign in MRI was diagnosed as follows [19]: lesions frequently seen in the basal ganglia, thalami, and midbrain, hyperintensity on T2-weighted images and fluid attenuated inversion recovery (FLAIR) images without contrast enhancement.

\section{Therapy}

The 108 patients received treatment with an intravenous administration of amphotericin B deoxycholate (AmBd), which was given at $0.1 \mathrm{mg} / \mathrm{kg}$ the first day, $0.5 \mathrm{mg} / \mathrm{kg}$ the second day and was increased to $1 \mathrm{mg} / \mathrm{kg}$ per day from the third day, together with an oral 5-fluorocytosine (5-FC) at $100 \mathrm{mg} / \mathrm{kg}$ per day and fluconazole (FCZ) at $400 \mathrm{mg}$ per day, once they were diagnosed with CM. After 4-6 weeks of induction treatment, if the genus Cryptococcus spp. was no longer present in at least three sequential CSF examinations by microscopy, we stopped AmBd. We continued to use FCZ and 5-FC for 6-9 more months. The patients with persistent high intracranial pressure received a lumber puncture every 2 or 3 days to relieve their symptoms.

\section{Data analysis}

For comparison of continuous variables, such as age, CSF pressure, CSF protein, CSF glucose level, ratio of CSF glucose-to-blood glucose, hospitalization length and survival time, an independent sample t-test was performed. Chi-square test was used to compare the categorical variable, including bird/ bird dropping contact history, potential risk factors, symptoms, EEGs, MRI results and outcome status between female and male. Multivariate analysis was performed for detection of the contributors to the onset of $\mathrm{CM}$ in female patients. The independent variables for multivariate analysis were selected according to statistical significance in univariate analysis. Furthermore, Cox regression model was used to evaluate the factors related to survival length. Statistical significance was defined as $p<0.05$ and data was analyzed using SPSS 16.0 software (SPSS, Chicago, IL, USA).

\section{Results}

Among the $108 \mathrm{CM}$ patients collected from Nanfang Hospital, 31 of them were female (Mean age33.55 \pm 15.65 years old; Range 5-63 years old). Average time interval from illness onset to hospitalization was $47.48 \pm$ 82.42 days. Two cases had clear history of exposure to 
bird/bird droppings. There were 19 of 31 cases (61.3\%) that had potential risk factors. The most common potential risk factor was chronic use of corticosteroids or other immunosuppressants (10 cases, $32.3 \%$ ), and then SLE or other autoimmune diseases ( 9 cases, $29.0 \%$ ), kidney diseases ( 3 cases, $9.7 \%$ ), diabetes mellitus (1 case, $3.2 \%$ ), tuberculosis (1 case, $3.23 \%$ ), hyperthyroidism (1 case, $3.23 \%$ ), pregnant (1 case, $3.23 \%$ ), hepatitis B infection (1 case, $3.23 \%)$ and gastric ulcer (1 case, $3.23 \%$ ) (Table 1). Compared with male patients, the history of SLE or other antoimmune diseases and the use of corticosteroids and/or other immunosuppressants had more relationship to the onset of $\mathrm{CM}$ in female patients.

Nonspecific symptoms, such as headache (24 cases, $77.42 \%)$ and fever (19 cases, $61.29 \%$ ) were frequently found in female CM patients, while seizures (3 cases, $9.7 \%$ ), dizziness (1 case, $3.2 \%$ ), ataxia (1 case, $3.2 \%$ ) and psychosis ( 2 cases, $6.5 \%$ ) were rare. Although female were more inclined to visit a doctor because of unconsciousness ( $25.8 \%$ vs. $14.3 \%)$, seizures (9.7\% vs. $6.5 \%)$ and dizziness (3.2\% vs. $1.3 \%$ ), there was no statistical difference (Table 2). In addition, there was no difference between male and female in the first CSF results, containing CSF pressure, CSF glucose level, CSF protein, the ratio of CSF glucose-to-blood glucose, EEG examinations, and MRI results (Table 2).

Table 1 Demographic characteristics, contact history and risk factors related to gender in CM patients

\begin{tabular}{|c|c|c|c|}
\hline & $\begin{array}{l}\text { Male } \\
(n=77)\end{array}$ & $\begin{array}{l}\text { Female } \\
(n=31)\end{array}$ & $P$ \\
\hline \multicolumn{4}{|l|}{ Demographic characteristics } \\
\hline Age (years), mean $\pm S D$ & $\begin{array}{l}38.95 \pm \\
18.32\end{array}$ & $\begin{array}{l}33.55 \pm \\
15.65\end{array}$ & 0.15 \\
\hline Contact history, no. (\%) & $3(3.9)$ & $2(1.4)$ & 0.624 \\
\hline \multicolumn{4}{|l|}{ Risk factors } \\
\hline $\begin{array}{l}\text { Use of corticosteroids and/or } \\
\text { immunosuppressants, no. (\%) }\end{array}$ & $9(11.7)$ & $10(32.3)$ & $0.011^{*}$ \\
\hline $\begin{array}{l}\text { History of SLE or other } \\
\text { autoimmune diseases, no. (\%) }\end{array}$ & $3(3.9)$ & $9(29)$ & $<0.001^{*}$ \\
\hline $\begin{array}{l}\text { History of kidney diseases }{ }^{a} \text {, } \\
\text { no. (\%) }\end{array}$ & $1(1.3)$ & $3(9.7)$ & 0.07 \\
\hline History of hematopathy, no. (\%) & $2(2.6)$ & $0(0)$ & 0.506 \\
\hline History of DM, no. (\%) & $4(5.2)$ & $1(3.2)$ & 0.554 \\
\hline History of TB, no. (\%) & $5(6.5)$ & $1(3.2)$ & 0.444 \\
\hline $\begin{array}{l}\text { History of other diseases }{ }^{\mathrm{b}} \text {, } \\
\text { no. (\%) }\end{array}$ & $2(2.6)$ & $3(9.7)$ & 0.145 \\
\hline $\begin{array}{l}\text { History of malignant cancer, } \\
\text { no. (\%) }\end{array}$ & $1(1.3)$ & $0(0)$ & 0.713 \\
\hline $\begin{array}{l}\text { History of organ transplantation, } \\
\text { no. (\%) }\end{array}$ & $1(1.3)$ & $0(0)$ & 0.713 \\
\hline
\end{tabular}

Table 2 Clinical features and outcome related gender in CM patients

\begin{tabular}{|c|c|c|c|}
\hline & Male $(n=77)$ & Female $(n=31)$ & $P$ \\
\hline \multicolumn{4}{|l|}{ Symptoms } \\
\hline Headache, no. (\%) & $57(74.0)$ & $24(77.4)$ & 0.713 \\
\hline Fever, no. (\%) & $48(62.3)$ & $19(61.3)$ & 0.919 \\
\hline Seizure, no. (\%) & $5(6.5)$ & $3(9.7)$ & 0.687 \\
\hline Dizziness, no. (\%) & $1(1.3)$ & $1(3.2)$ & 0.494 \\
\hline Ataxia, no. (\%) & $3(3.9)$ & $1(3.2)$ & 1 \\
\hline Unconsciousness, no. (\%) & $11(14.3)$ & $8(25.8)$ & 0.155 \\
\hline Psychosis, no. (\%) & $2(2.6)$ & $2(6.5)$ & 0.577 \\
\hline \multicolumn{4}{|l|}{$\mathrm{CSF}$, mean $\pm \mathrm{SD}$} \\
\hline $\begin{array}{l}\text { Ratio of CSF glucose/Blood } \\
\text { glucose, mean } \pm \text { SD }\end{array}$ & $0.30 \pm 0.18$ & $0.28 \pm 0.18$ & 0.54 \\
\hline $\begin{array}{l}\text { CSF pressure }(\mathrm{mmH} 2 \mathrm{O}) \\
\text { mean } \pm \mathrm{SD}\end{array}$ & $266.49 \pm 60.13$ & $271.94 \pm 49.49$ & 0.66 \\
\hline $\begin{array}{l}\text { CSF glucose }(\mathrm{mmol} / \mathrm{L}) \text {, } \\
\text { mean } \pm \mathrm{SD}\end{array}$ & $2.08 \pm 1.36$ & $1.64 \pm 1.01$ & 0.80 \\
\hline $\begin{array}{l}\text { CSF protein }(g / L) \\
\text { mean } \pm S D\end{array}$ & $0.94 \pm 1.53$ & $0.86 \pm 0.51$ & 0.11 \\
\hline Abnormal EEG ${ }^{a}$, no. (\%) & $17(68.0)$ & $10(76.9)$ & 0.71 \\
\hline Abnormal MRl' ${ }^{b}$, no. (\%) & $25(75.8)$ & $9(60.0)$ & 0.31 \\
\hline \multicolumn{4}{|l|}{ Outcome } \\
\hline $\begin{array}{l}\text { Hospitalization length } \\
\text { (days), mean } \pm \mathrm{SD}\end{array}$ & $50.71 \pm 55.36$ & $53.35 \pm 53.93$ & 0.44 \\
\hline $\begin{array}{l}\text { Survival time (months), } \\
\text { mean } \pm S D\end{array}$ & $30.40 \pm 45.30$ & $21.22 \pm 36.15$ & 0.09 \\
\hline Dead, no. (\%) & $30(45.5)$ & $15(53.6)$ & 0.47 \\
\hline
\end{tabular}

${ }^{a}$ Abnormal EEG included 5 cases had normal background with focal slow wave and 5 had diffused slow wave in the background

${ }^{\mathrm{b}}$ Abnormal MRI included Bubble sign 5 cases $(2$ at the basal ganglion and 3 at subcortex), hydrocephalus 5 cases and 6 cases with abnormal cerebral lesions ( 6 cases with more than one abnormal features)

There was no difference of hospitalization length ( $53.35 \pm 53.93$ days vs. $50.71 \pm 55.36$ days, $p=0.44$ ) and survival time $(21.22 \pm 36.15$ months vs. $30.40 \pm 45.30$ months, $p=0.09$ ) between female and male CM patients. The mortality of female CM patients was slightly higher (15 cases, $53.6 \%$ ) than male (30 cases, $45.5 \%$ ), but without statistical significance (Table 2).

On our univariate analysis, use of corticosteroids and/ or immunosuppressants (32.3\% versus $11.7 \% ; p=0.011$ ) and history of SLE or other autoimmune diseases (29\% versus $3.9 \% ; p<0.001$ ) were significantly higher in female $\mathrm{CM}$ patients. However, on multivariate analysis, we found history of SLE or other autoimmune diseases was significant between genders (odds ratio (OR) 10.59, 95 \% confidence interval (CI) 1.49-74.77, $p=0.02$ ), while the use of corticosteroids and/or immunosuppressants was not (OR 0.94, 95 \% CI 0.18-4.86, $p=0.95$ ) (Table 3).

Cox regression analysis of female CM patients demonstrated that the decreased ratio of CSF glucose-to-blood 
Table 3 Multivariate conditional logistic analysis of independent risk factors for onset of CM in female patients $(n=31)$

\begin{tabular}{|c|c|c|c|c|c|c|}
\hline & \multicolumn{3}{|c|}{ Univariate analysis } & \multicolumn{3}{|c|}{ Multivariate analysis } \\
\hline & $\overline{\mathrm{OR}}$ & $95 \% \mathrm{Cl}$ & $P$ & $\overline{\mathrm{OR}}$ & $95 \% \mathrm{Cl}$ & $P$ \\
\hline $\begin{array}{l}\text { Use of } \\
\text { corticosteroids and/or } \\
\text { immunosuppressants }\end{array}$ & 2.23 & $1.27-3.93$ & $0.011^{*}$ & 0.94 & $0.18-4.86$ & 0.95 \\
\hline $\begin{array}{l}\text { History of SLE or } \\
\text { other autoimmune } \\
\text { diseases }\end{array}$ & 3.27 & $2.00-5.35$ & $<0.001^{*}$ & 10.59 & $1.49-74.77$ & $0.02^{*}$ \\
\hline
\end{tabular}

glucose was significantly related to survival time in female patients $(p=0.03,95 \%$ CI $0-0.71)$ while decreased consciousness $(p=0.18,95 \%$ CI $0.07-1.65)$ and CSF pressure $(p=0.41,95 \%$ CI $0.99-1.00)$ were not (Table 4$)$.

\section{Discussion}

The genus Cryptococcus spp. can infect almost all organs in the human body, but the site of serious consequence is the central nervous system [2, 3]. Despite the improvements in diagnosis and management, lack of specific symptoms, long hospitalization and high mortality still make CM a significant challenge to clinical works $[20,21]$. In this study, we compared the demographic and clinical features of 31 female and 77 male CM patients, and attempted to analyze the independent risk factor for onset of CM in female and the factors related to their survival time.

The results of this study revealed several significant features between female and male CM patients. In female CM patients, use of corticosteroids and/or immunosuppressants and the history of SLE or other autoimmune diseases were more common, but history of SLE or other autoimmune diseases was the only clinical risk factor independently contributed to the onset. Similar to our results from a previous study involving the whole population [9], the ratio of CSF glucose-to-blood glucose was the only factor related to the survival length of female CM patients.

Kwon et al. [18] suggested several risk factors for CM including HIV infection, malignancies, cirrhosis, organ transplantation, end-stage renal failure autoimmune disorder, diabetes mellitus, idiopathic CD4 T-cell lymphopenia, sarcoidosis, chronic usage of corticosteroids or

Table 4 Cox regression analysis of risk factors for survival length of female cryptococcal meningoencephalitis patients

\begin{tabular}{llll}
\hline Risk factors & $\mathrm{P}$ & $\mathrm{OR}$ & $95 \% \mathrm{Cl}$ \\
\hline Decreased consciousness level & 0.18 & 0.345 & $0.07-1.65$ \\
CSF pressure & 0.41 & 0.996 & $0.99-1.00$ \\
The ratio of CSF glucose/ blood glucese & $0.03^{*}$ & 0.018 & $0.00-0.71$ \\
${ }^{*} P<0.05$ & & &
\end{tabular}

other immunosuppressive therapy. While Yuchong et al. [3] found that tuberculosis and liver diseases were more common potential risk factors in China. Additionally, Guo et al. [22] suggested contact with birds/bird droppings or saprophytes before illness onset in children. In our study, the gender-specific risk factors in female CM were use of corticosteroids and/or immunosuppressants and the history of SLE or other autoimmune diseases. This can probably be explained due to the marked gender predilections with women more commonly afflicted than men.

Surprisingly, the history of SLE or other autoimmune diseases rather than the chronic use of corticosteroids and/ or immunosuppressants were the independent genderspecific contributing risk factor to onset of CM in female patients. Previous studies reported that efficient control of cryptococcal infection requires a delicate balance of both Th1- and Th2- type responses [23, 24]. It probably because that $\mathrm{T}$ cells play a major role in SLE by amplifying the autoimmune response leading to a misbalance of the downstream cytokines [25], while the balance remains in the inhibition of T-cell proliferation and activation caused by use of corticosteroids and immunosuppressants. This result demonstrated that once diagnosed with SLE or other autoimmune diseases, the female patients should be given prevention of the cryptococcal infection, independent of chronic use of corticosteroids or other immunosuppressants.

Decreased consciousness level, a lower CSF opening pressure and the decreased ratio of CSF glucose-toblood glucose were reported contributed to CM prognosis [26]. In our study, decreased ratio of CSF glucoseto-blood glucose was the only factor related to the survival length of female CM patients. This result illustrated that the female CM patients who had decreased ratio of CSF glucose-to-blood glucose in the first CSF analysis should monitored closely during the therapy process, for they may have longer hospitalization time and higher mortality.

This study had limitations inherent to all retrospective studies, such as inconsistencies in patients care. Another limitation results from lost contact with cases during the follow-up process, particularly of cases in rural areas where it is difficult to reach by mail, phone or car. One of the strengths of our study is firstly demonstrating the gender-specific risk factor for the onset of CM in female patients as well as our use of Cox regression analysis to assess the factors related to survival time in them.

\section{Conclusions}

The genus Cryptococcus spp. infection of CNS increased in female patients in recent years. Use of corticosteroids or other immunosuppressants and history of SLE and other autoimmune diseases were more common in females than males. However, the history of SLE or other 
autoimmune diseases rather than chronic use of corticosteroids and/or immunosuppressants was the independent gender-specific contributing risk factor to onset of $\mathrm{CM}$ in female patients. Decreased ratio of CSF glucose-to-blood glucose in the CSF analysis before antifungal therapy predicted the worse prognosis. So once diagnosed with SLE or other autoimmune diseases, the female patients should be given prevention of the cryptococcal infection, independent of chronic use of corticosteroids or other immunosuppressants. Furthermore the female patients who had decreased ratio of CSF glucose-to-blood glucose in the first CSF analysis should be monitored closely during the therapy process.

\section{Abbreviations}

5-FC: 5-fluorocytosine; AmBd: amphotericin B; Cl: confidence interval; CM: cryptococcal meningoencephalitis; CNS: central nervous system; CSF: cerebrospinal fluid; EEG: electroencephalograph; FCZ: fluconazole; FLAIR: fluid attenuated inversion recovery; MRI: magnetic resonance imaging; OR: odds ratio; SD: standard deviation; SLE: systemic lupus erythematosus.

\section{Competing interests}

The authors declare that they have no competing interests.

\section{Authors' contributions}

SYP conceived the design for this study, and $\mathrm{HZ}$ drafted the manuscript. SYP revised the manuscript in detail. MYL and WDM collected the data, MYL and JLY performed the statistical analysis. QC, XMZ, MY, JYL and NFC made significant contributions to this work by providing assistance and helped in the data collection, data handling and analysis. All authors read and approved the final manuscript.

\section{Authors' information}

Hui Zheng is an attendant at the Department of Neurology in Nanfang hospital, the first affiliated hospital of the Southern Medical University. She completed her Ph.D. degree within the First Affiliated Hospital of Sun-Yet Sen University in Guangzhou and she studied in the University of North Carolina in the United States. Her research focuses on the investigation of neuromuscular diseases and CNS infections.

\section{Acknowledgements}

A very special thank you is given to Tejash Patel (University of North Carolina, USA) for the contribution to the language of this article.

\section{Author details}

'Department of Neurology, Nanfang Hospital, Southern Medical University, No.1838 North Guangzhou Avenue, Guangzhou City, Guangdong Province, People's Republic of China. ${ }^{2}$ Medical Records Room, Nanfang Hospital, Southern Medical University, Guangzhou City, Guangdong Province, People's Republic of China.

Received: 11 August 2015 Accepted: 18 January 2016

Published online: 22 January 2016

\section{References}

1. Tay ST, Rohani MY, Hoo TS, Hamimah H. Epidemiology of cryptococcosis in Malaysia. Mycoses. 2010;53(6):509-14.

2. Vazquez-Gonzalez D, Perusquia-Ortiz AM, Hundeiker M, Bonifaz A. Opportunistic yeast infections: candidiasis, cryptococcosis, trichosporonosis and geotrichosis. J Dtsch Dermatol Ges. 2013;11(5):381-93. quiz 394.

3. Yuchong C, Fubin C, Jianghan C, Fenglian W, Nan X, Minghui Y, et al. Cryptococcosis in China (1985-2010): review of cases from Chinese database. Mycopathologia. 2012;173(5-6):329-35.

4. Sloan DJ, Parris V. Cryptococcal meningitis: epidemiology and therapeutic options. Clin Epidemiol. 2014:6:169-82.

5. Legato MJ. Principles of gender-specific medicine. UK: Elsevier; 2010.
6. Kuller RBNLH. Health and disease among women: biological and environmental influences, vol. 15. New York: Oxford University Press; 1999.

7. Pyrgos V, Seitz AE, Steiner CA, Prevots DR, Williamson PR. Epidemiology of cryptococcal meningitis in the US: 1997-2009. PLoS One. 2013;8(2):e56269.

8. Tintelnot K, Lemmer K, Losert H, Schar G, Polak A. Follow-up of epidemiological data of cryptococcosis in Austria, Germany and Switzerland with special focus on the characterization of clinical isolates. Mycoses. 2004; 47(11-12):455-64.

9. Z Zheng H, Li M, Luo Y, Wang D, Yang J, Chen Q, et al. A retrospective study of contributing factors for prognosis and survival length of cryptococcal meningoencephalitis in Southern part of China (1998-2013). BMC Infect Dis. 2015;15(1):77.

10. Chen $Y Y$, Lai CH. Nationwide population-based epidemiologic study of cryptococcal meningitis in Taiwan. Neuroepidemiology. 2011;36(2):79-84.

11. Friedman GD, Jeffrey Fessel W, Udaltsova NV, Hurley LB. Cryptococcosis: the 1981-2000 epidemic. Mycoses. 2005;48(2):122-5.

12. Niknam N, Niknam N, Dushaj K, Restrepo E. A case of recurrent cryptococcal meningoencephalitis in an immunocompetent female. Case Rep Infect Dis. 2014:2014:407348

13. Costa ML, Souza JP, Oliveira Neto AF, Pinto ESJL. Cryptococcal meningitis in HIV negative pregnant women: case report and review of literature. Rev Inst Med Trop Sao Paulo. 2009:51(5):289-94.

14. Tang WK, Hui M, Ungvari GS, Leung CM. Cryptococcal meningitis mimicking primary mania in a young female. Gen Hosp Psychiatry. 2005; 27(4):301-3.

15. Vawda F, Maharajh J, Naidoo K. Massive cryptococcal lymphadenopathy in an immunocompetent pregnant patient. Br J Radiol. 2008;81(962):e53-6.

16. Nayak SU, Talwani R, Gilliam B, Taylor G, Ghosh M. Cryptococcal meningitis in an HIV-positive pregnant woman. J Int Assoc Phys AIDS Care. 2011;10(2):79-82.

17. Bestard J, Siddiqi ZA. Cryptococcal meningoencephalitis in immunocompetent patients: changing trends in Canada. Neurology. 2010; 74(15):1233-5.

18. Kwon-Chung K, Bennett JE, editors. Medical mycology. Piladelphia: Lea \& Febiger; 1992.

19. Kwee RM, Kwee TC. Virchow-Robin spaces at MR imaging. Radiographics. 2007;27(4):1071-86

20. Kwan CK, Leelawiwat W, Intalapaporn P, Anekthananon T, Raengsakulrach B, Peters PJ, et al. Utility of cryptococcal antigen screening and evolution of asymptomatic cryptococcal antigenemia among HIV-infected women starting antiretroviral therapy in Thailand. J Int Assoc Provid AIDS Care. 2014; 13(5):434-7.

21. Mora DJ, da Cunha Colombo ER, Ferreira-Paim K, Andrade-Silva LE, Nascentes GA, Silva-Vergara ML. Clinical, epidemiological and outcome features of patients with cryptococcosis in Uberaba, Minas Gerais, Brazil. Mycopathologia. 2012;173(5-6):321-7.

22. Guo J, Zhou J, Zhang S, Zhang X, Li J, Sun Y, et al. A case-control study of risk factors for HIV-negative children with cryptococcal meningitis in Shi Jiazhuang, China. BMC Infect Dis. 2012;12:376.

23. Lindell DM, Ballinger MN, McDonald RA, Toews GB, Huffnagle GB. Diversity of the T-cell response to pulmonary Cryptococcus neoformans infection. Infect Immun. 2006;74(8):4538-48.

24. Coelho C, Bocca AL, Casadevall A. The intracellular life of Cryptococcus neoformans. Annu Rev Pathol. 2014;9:219-38.

25. Comte D, Karampetsou MP, Tsokos GC. T cells as a therapeutic target in SLE. Lupus. 2015;24(4-5):351-63.

26. Darze C, Lucena R, Gomes I, Melo A. Prognosis factors in cryptococcal meningoencephalitis. Arq Neuropsiquiatr. 1999;57(3A):649-52. 